\title{
Activated Carbon via. Pyropysis of Tea Industry Waste Biochar with KOH Activation: Preparation and Characterization
}

\author{
${ }^{1}$ Thuan Van Tran, ${ }^{1}$ Bich Ngoc Hoang, ${ }^{1}$ Hien Thien Tran, ${ }^{1}$ Nhan Phu Thuong Nguyen, \\ ${ }^{2}$ Van Thi Thanh Ho, ${ }^{3,4}$ Nguyen Dai Hai, ${ }^{1}$ Vu Dai Cao, ${ }^{1}$ Trinh Duy Nguyen and ${ }^{1,3}$ Long Giang Bach \\ ${ }^{1}$ Nguyen Tat Thanh University, Ho Chi Minh City, Vietnam \\ ${ }^{2}$ Hochiminh University of Natural Resources and Environment (HCMUNRE), Ho Chi Minh City, Vietnam \\ ${ }^{3}$ Vietnam Academy of Science and Technology, Graduate University of Science and Technology, \\ Hanoi, Vietnam \\ ${ }^{4}$ Institute of Applied Materials Science, Vietnam Academy of Science and Technology, \\ Ho Chi Minh City, Vietnam
}

\begin{abstract}
Tea waste is a abundant and low-cost biomass resource for preparation of Activated Carbons (ACs) The present study addressed a pyrolysis route using $\mathrm{KOH}$ as an activating agent to develop with new pores of the ACs from tea industry waste. The effects of activation temperatures $\left(600-800^{\circ} \mathrm{C}\right)$ on the structure of $\mathrm{ACs}$ were investigated. Characteristics of $\mathrm{ACs}$ were analyzed by several physical techniques such as analysis methods including X-Ray Diffraction (XRD), Scanning Electron Microscope (SEM), Thermo-Gravimetric Analysis (TGA) and nitrogen adsorption/desorption. The characterization results indicated that the as-synthesized ACs possess amorphous structure for all activation temperatures and the largest BET specific surface area $\left(1107.5 \mathrm{~m}^{2} / \mathrm{g}\right)$ accompanied with the highest pore volume $\left(0.579 \mathrm{~cm}^{3} / \mathrm{g}\right)$ at $800^{\circ} \mathrm{C}$. The average micropore size fluctuated in the range of 5-7 $\AA$ depending on the activation temperature. Therefore, the $\mathrm{KOH}$-activated carbons with high porosity can offer a great adsorption capacity as promising for applications in many areas especially in removal of environmental pollutants.
\end{abstract}

$\underline{\text { Key words: Activated carbon, tea industry waste, } \mathrm{KOH} \text { activation, characterization, environmental, pollutants }}$

\section{INTRODUCTION}

Nanoporous materials have widely applied in a various range of fields such as catalysis, adsorption, hydrogen storage, drug delivery and electronics (Liu et al., 2015). Recently, Activated Carbons (ACs) are considered as sustainable and promising materials because they possess many kinds of precious chemical and physical properties including large surface area, high porosity and diverse functional groups on surface (Van Tran et al., 2017; Giang et al., 2017; Bach et al., 2018). However, commercial ACs are often expensive, therefore, utilization of biomass as a carbonaceous source for the synthesis of activated carbon has paid much attention because of its abundance and green productivity (Gundogdu et al., 2012).

The synthesis strategies towards an ordered mesoporous structure is highly desirable because adsorptive molecules are likely to approach the inner mesopores via. diffusion pathways (Nor et al., 2013). However, formation of micropores on activated carbons can increase the number of "adsorption sites" which allow to link between adsorbates and these sites (Juarez-Galan et al., 2009). Thus, the development of new pores in micro and meso-sizes is essential to augment both high adsorption capacity and adsorption kinetics for capturing larger molecules.

To obtain a micro and meso-porosity, transformation of biomass from lignocellulosic precursors into porous carbon materials needs to be carried out by physical pathways using $\mathrm{CO}_{2}$ and or chemical activation procedures using $\mathrm{KOH}$ or $\mathrm{H}_{3} \mathrm{PO}_{4}$ under aerobic conditions (Tran et al., 2017). In carbonization via physical methods, precursors are firstly pyrolyzed at elevated temperatures at around $200^{\circ} \mathrm{C}$ to release a large amount of volatiles such as $\mathrm{H}_{2} \mathrm{O}$ and $\mathrm{CO}$ and develop the porosity (Uysal et al., 2014). At higher temperature, physical activators such as $\mathrm{CO}_{2}$ or steam tend to arrange the structure with higher porosity.

In chemical activation pathway, chemical agents $\left(\mathrm{ZnCl}_{2}, \mathrm{H}_{3} \mathrm{PO}_{4}, \mathrm{KOH}, \mathrm{K}_{2} \mathrm{CO}_{3}\right.$ ) can be used to soak with raw materials or their biochar by chemical impregnation (Reffas et al., 2010). This process facilitates to penetrate chemical molecules into precursor structure. Under high

Corresponding Author: Trinh Duy Nguyen, Nguyen Tat Thanh University, Ho Chi Minh City, Vietnam 
temperature and absence of oxygen, reaction between carbon atoms and chemical agents via oxidation can develop new pores (Farahania et al., 2011). However, among the well known chemical activation agents, $\mathrm{KOH}$ meets the environmentally friendly and economical requirements. Stefana and co-workers reported that $\mathrm{KOH}$ activation of carbon-based materials gave an adjustable microstructure and large specific surface area $3000 \mathrm{~m}^{2} / \mathrm{g}$ for use in hydrogen storage adsorbents and electrode materials (Wang and Kaskel, 2012). Ruiz also demonstrated $\mathrm{KOH}$ as an effective activator for the synthesis of microwave-assisted conventional ACs from macroalgae waste, giving rise to surface area $\left(2118 \mathrm{~m}^{2} / \mathrm{g}\right)$ and pore volume $\left(1.14 \mathrm{~cm}^{3} / \mathrm{g}\right.$ ) (Ferrera-Lorenzo et al., 2014).

Moreover, characteristics of ACs are dependent on preparation conditions, especially, concentration of activating agent, impregnation ratio and activation temperature. Yang Li and co-workers used $\mathrm{KOH} 6 \mathrm{~mol} / \mathrm{L}$ with impregnation ratio $1: 2$ for activating polyacrylonitrile based pre-oxidized fiber $\mathrm{AC}$ during $1 \mathrm{~h}$ at $800^{\circ} \mathrm{C}$, creating a mesoporosity form with surface area of $3029 \mathrm{~m}^{2} / \mathrm{g}$ (Guo et al., 2017).

Green tea is cultivated in some tropical countries, producing tea industry products. Along with increased consumption, tea waste by-products can often be used as simple organic fertilizers, even discharged without any pretreatment. Therefore, taking advantage of tea industry waste is necessary to synthesize the green porous carbon. The present study addresses the fabrication and characterization of the ACs derived from Vietnamese tea-industry wastes using $\mathrm{KOH}$ as an efficient activating agent. Influence of activation temperatures $\left(600-800^{\circ} \mathrm{C}\right)$ on the properties resulting activated carbons such as surface area, functional group and morphological patterns was studied. Moreover, through fabrication conditions, the product yields were also measured.

\section{MATERIALS AND METHODS}

\section{Experiment}

Chemicals and instruments: All chemicals mentioned were commercially purchased from Merck. XRD analysis was performed on a D8 Advance Bruker powder diffractometer using $\mathrm{Cu}-\mathrm{K} \alpha$ excitation source at room temperature. The morphology of the materials was characterized using scanning electron microscopy with S-4800 instrument (Japan). To determine the surface chemistry, FT-IR spectra of samples were recorded at room temperature in the wavenumber range of 4000-400 $\left(\mathrm{cm}^{-1}\right)$ by a Nicolet 6700 spectrophotometer instrument.
The weight change was examined using a TGA Q500 Universal V4.5A instrument at various temperatures $(0-900$ $10^{\circ} \mathrm{C} / \mathrm{min}$ ). The nitrogen adsorption/desorption isotherms at $196^{\circ} \mathrm{C}$ were measured using a Micromeritics 2020 volumetric adsorption analyzer. The samples were degassed in vacuum pressure at $150^{\circ} \mathrm{C}$ for $6 \mathrm{~h}$ before any measurement. The specific surface area was determined by BET isotherm equation and the micro-pore volume was calculated according to Dubinin-Radushkevich (DR) equations. The pore size distribution was illustrated by Non-Local Density Functional Theory (NLDFT).

Synthesis of activated carbon: Tea industry waste was collected and washed with distilled water in order to eliminate impurities, followed by drying under sunshine. The pretreated precursors were crushed, sieved to the desired particle size $(<1 \mathrm{~mm})$ and then stored in sealed bags for further use.

The synthesis of $\mathrm{AC}$ was conducted via two stages. Firstly, $30 \mathrm{~g}$ of the dried tea wastes were placed on a heat resistant ceramic connecting an electric furnace and heated up from room temperature to $400^{\circ} \mathrm{C}$ for $1 \mathrm{~h}$ under nitrogen atmosphere $\left(400 \mathrm{~cm}^{3} / \mathrm{min}\right)$. After calcination finished, thermal decomposition was cooled down overnight. The biochar product ( $2 \mathrm{~g}$ ) was soaked with $\mathrm{KOH}$ aqueous solution with impregnation ratio 1:1 overnight and dried for $24 \mathrm{~h}$.

Next, the $\mathrm{KOH}$-impregnated biochar was placed on the same electric furnace system but temperature was set up at $600-800^{\circ} \mathrm{C}$ (labeled as TW600-TW800, respectively). The pyrolysis was maintained stable during next $2 \mathrm{~h}$. Finally, the AC samples were repeatedly washed with deionized water and neutrialized until $\mathrm{pH}=7$. The as-prepared activated carbon was dried at $105^{\circ} \mathrm{C}$, ground to fine powder and stored for further uses.

\section{RESULTS AND DISCUSSION}

XRD spectra of the AC samples: To compare the effect of production temperature on crystalline structure of $\mathrm{AC}$ samples, the samples were conducted at $600-800^{\circ} \mathrm{C}$ and their XRD spectra were shown in Fig. 1. For all samples, the diagnostic plots generally reflect the same trend. Typical peaks of activated carbons, at around $26-44^{\circ}$ related to (002) and (100) Bragg reflections were observed for all samples, revealing predominantly amorphous structure. Moreover, the very broad (002) lines can be attributed to a small number of stacked layers while random turbostratic stacking of layers may make up (100) lines (Srenscek-Nazzal et al., 2013). Moreover, the 


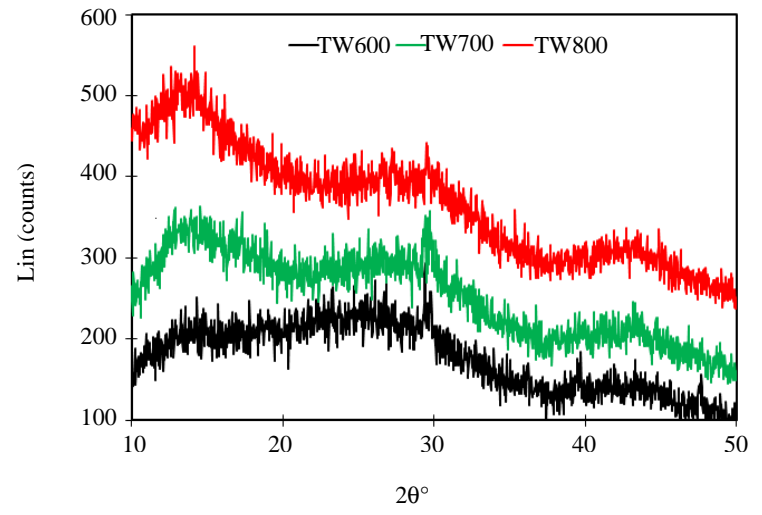

Fig. 1: XRD spectra of the AC samples (TW600-TW800)

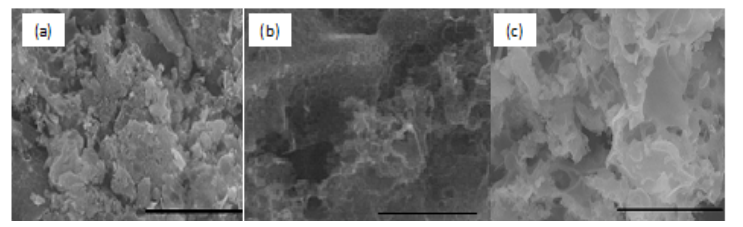

Fig. 2: SEM images of the ACs: a) TW600 (b)TW700; c) TW800. The scale bar is equivalent to $5 \mu \mathrm{m}$

existence of small sharp signals near $30^{\circ}$ is much likely related to the residual ash (Xu et al., 2014).

Morphological patterns of the AC samples: SEM patterns were used to reveal the morphological surface of the $\mathrm{AC}$ samples. Figure 2 shows the amorphous, defect-rich and heterogeneous structure of the ACs. The structures generally tend to reach a more porosity at higher activation temperatures. Especially, highly porous activated carbons could be observed clearly with the activated carbons from $700-800^{\circ} \mathrm{C}$ and the inner structure constitute more new pores at $800^{\circ} \mathrm{C}$. The construction of pore system during high-temperature activation could be attributed to rapid release of volatile matters $\left(\mathrm{CO}_{2}\right.$ and $\mathrm{H}_{2} \mathrm{O}$ ) which normally resulted in formation of macro spaces and then the chemicals replace with these positions, facilitate $\mathrm{KOH}$ molecules to react with carbon atoms and form new pores.

\section{Adsorption and desorption isotherms of the $\mathrm{AC}$ samples:}

According to $\mathrm{N}_{2}$ adsorption/desorption measurement, higher activation temperature offered higher BET surface area and DA pore volume but generally led to a decrease trend in the average pore size of the resulting activated carbons. The characteristic parameters of TW600-TW800 are listed in Table 1. In details, the highest BET surface area was achieved at $1107.5 \mathrm{~m}^{2} / \mathrm{g}$ of TW800

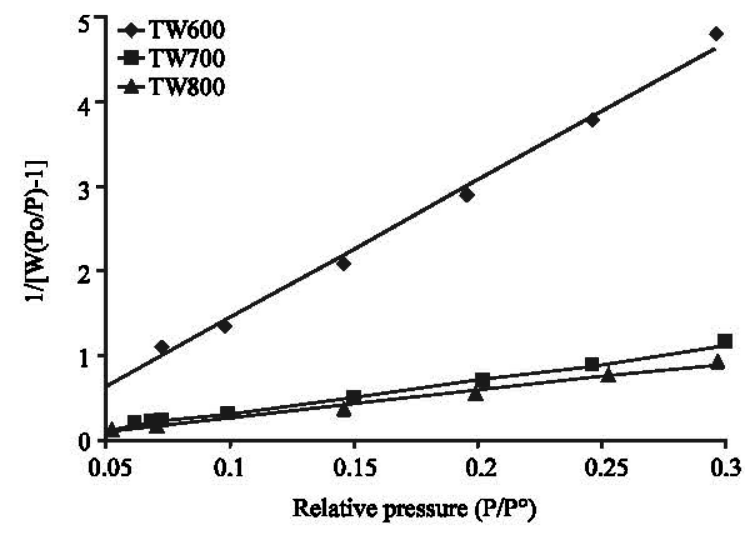

Fig. 3: BET surface area plot of the AC

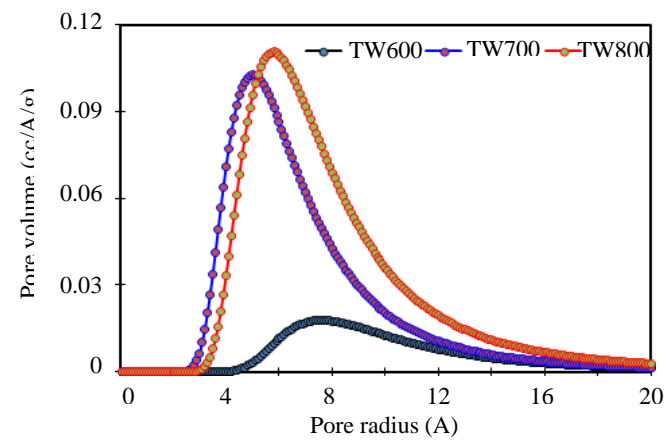

Fig. 4: Pore size distribution of the $\mathrm{AC}$ samples

followed by $910.0 \mathrm{~m}^{2} / \mathrm{g}$ of TW700 and $215.4 \mathrm{~m} / \mathrm{g}$ of TW600 as derived from their corresponding BET surface area plots presented in Fig. 3. Likewise, the increase of activation temperature from $600-700^{\circ} \mathrm{C}$ induced a strong evolution of micro-pores thus resulting in an upsurge of pore volume from $0.118-0.579 \mathrm{~cm}^{3}$. Less significant increase of pore volume occurs as the activation temperature went up to $800^{\circ} \mathrm{C}$ (Fig. 4). TW700 has the lowest average pore size of $5 \AA$ while the highest one was $7.3 \AA$ belonging to TW600. The carbon yields of all samples were in the range of $26-30 \%$. A decrease in the yield of the carbon with increasing activation temperature was observed indicating more significant gasification of carbons at higher temperature.

Functional groups studies of the AC samples: The $\mathrm{KOH}$-activated carbons prepared at $600-800^{\circ} \mathrm{C}$ were characterized to expose the various kinds of the surface functional groups. FTIR spectra were recorded as presented in Fig. 5. For all samples, each broad band at around $3421 \mathrm{~cm}^{-1}$ reveal the activated carbons contain $\mathrm{O}-\mathrm{H}$ stretching vibration of hydroxyl functional groups, the adsorption peak at $1193 \mathrm{~cm}^{-1}$ attributable to residual crystalline cellulose, the broad band in the range of 
Table 1: Results from $\mathrm{N}_{2}$ adsorption/desorption measurement

\begin{tabular}{lccccccc}
\hline Samples & Activation agent & Activation temp. $\left({ }^{\circ} \mathrm{C}\right)$ & Impregnation ratio $(-)$ & AC yield $(\%)$ & Pore size $(\AA)$ & BET $\left(\mathrm{m}^{2} / \mathrm{g}\right)$ & DA volume $\left(\mathrm{cm}^{3} / \mathrm{g}\right)$ \\
\hline TW600 & $\mathrm{KOH}$ & 600 & 1.0 & 30.6 & 7.3 & 215.4 & 0.118 \\
TW700 & $\mathrm{KOH}$ & 700 & 1.0 & 27.7 & 5.0 & 910.0 & 0.486 \\
TW800 & $\mathrm{KOH}$ & 800 & 1.0 & 26.3 & 6.6 & 1107.5 & 0.579 \\
\hline
\end{tabular}

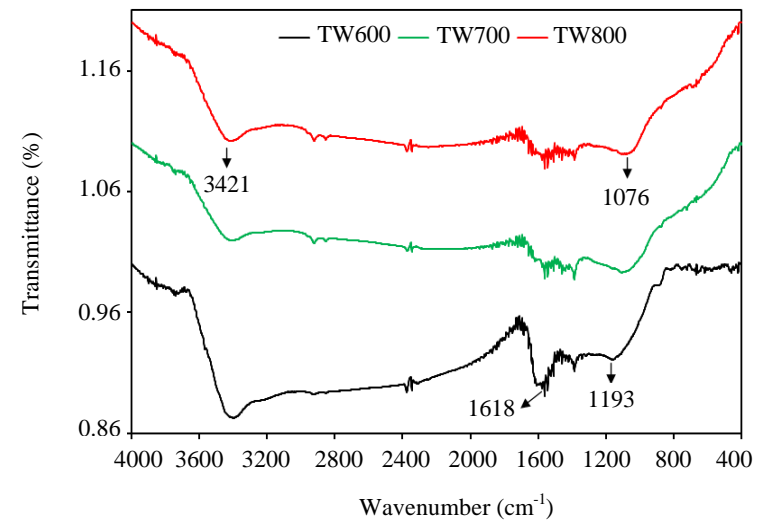

Fig. 5: FTIR spectra of the AC samples

$1000-1100 \mathrm{~cm}^{-1}$ ascribable to $\mathrm{C}-\mathrm{O}$ stretching and the bands in the range of $1550-1620 \mathrm{~cm}^{-1}$ corresponding to $\mathrm{C}=\mathrm{O}$ stretching for ketones, aldehydes or carboxyl groups and $\mathrm{C}-\mathrm{C}$ stretching of the aromatic ring (Farahania et al., 2011; Guo et al., 2017; Ncibi et al., 2014) As the activation temperature increased to 700 and $800^{\circ} \mathrm{C}$, the small peaks at around $2900 \mathrm{~cm}^{-1}$ ascribed to $\mathrm{C}-\mathrm{H}$ stretching appeared. Moreover, the peaks at $1193 \mathrm{~cm}^{-1}$ shifted to about $1076 \mathrm{~cm}^{-1}$ indicating a more significant contribution of C-O stretching (Van Thuan et al., 2017). Note that there was a considerable decrease in intensities of the bands of $\mathrm{O}-\mathrm{H}$ stretching as activation temperature increased from $600-700^{\circ} \mathrm{C}$, possibly resulted from the strong release of $\mathrm{OH}$ groups.

\section{CONCLUSION}

The highly porous $\mathrm{KOH}$-activated carbons were successfully synthesized from tea industry waste. Increasing activation temperature from $600-800^{\circ} \mathrm{C}$ increased the surface area and pore volume of the activated carbons. The highest surface area and pore volume were at $1107.5 \mathrm{~m}^{2} / \mathrm{g}$ and $0.579 \mathrm{~cm}^{3} / \mathrm{g}$, respectively as obtained on the activated carbon prepared at $800^{\circ} \mathrm{C}$. The SEM images and XRD spectra illustrated an amorphous and defect-rich structure. The surface chemistry of the activated carbon was dominated by $\mathrm{C}-\mathrm{O}$ and $\mathrm{OH}$ stretchings as determined by FTIR analysis.

\section{ACKNOWLEDGEMENT}

This research is funded by Foundation for Science and Technology Development Nguyen Tat Thanh University, Ho Chi Minh City, Vietnam.

\section{REFERENCES}

Bach, L.G., T. Van Tran, T.D. Nguyen, T. Van Pham and S.T. Do, 2018. Enhanced adsorption of methylene blue onto graphene oxide-doped $\mathrm{XFe}_{2} \mathrm{O}_{4}(\mathrm{X}=\mathrm{Co}, \mathrm{Mn}$, $\mathrm{Ni})$ nanocomposites: Kinetic, isothermal, thermodynamic and recyclability studies. Res. Chem. Intermed., 44: 1661-1687.

Farahania, M., S.R.S. Abdullaha, S. Hosseinib, S. Shojaeipourc and M. Kashisaza, 2011. Adsorption-based cationic dyes using the carbon active sugarcane bagasse. Proc. Environ. Sci., 10: 203-208.

Ferrera-Lorenzo, N., E. Fuente, I. Suarez-Ruiz and B. Ruiz, 2014. $\mathrm{KOH}$ activated carbon from conventional and microwave heating system of a macroalgae waste from the Agar-Agar industry. Fuel Process. Technol., 121: 25-31.

Gao, L., H. Lu, H. Lin, X. Sun and J. Xu et al., 2014. KOH direct activation for preparing activated carbon fiber from polyacrylonitrile-based pre-oxidized fiber. Chem. Res. Chin. Univ., 30: 441-446.

Giang, B.L., N.D. Trinh, P. Van Thinh and T. Thuan Van, 2017. Optimization of the fabrication of banana peel-derived activated carbon and application for $\mathrm{Cu}^{2}+$ removal. J. Mater. Sci. Surf. Eng., 5: 622-626.

Gundogdu, A., C. Duran, H.B. Senturk, M. Soylak and D. Ozdes et al., 2012. Adsorption of phenol from aqueous solution on a low-cost activated carbon produced from tea industry waste: Equilibrium, Kinetic and thermodynamic study. J. Chem. Eng. Data, 57: 2733-2743.

Guo, J.X., H.D. Luo, S. Shu, X.L. Liu and J.J. Li et al., 2017. Regeneration of $\mathrm{Fe}$ modified activated carbon treated by $\mathrm{HNO}^{3}$ for flue gas desulfurization. Energy Fuels, 32: 765-776.

Juarez-Galan, J.M., A. Silvestre-Albero, J. Silvestre-Albero and F. Rodriguez-Reinoso, 2009. Synthesis of activated carbon with highly developed mesoporosity. Microporous Mesoporous Mater., 117: 519-521.

Liu, H., J. Zhang, H.H. Ngo, W. Guo and H. Wu et al., 2015. Effect on physical and chemical characteristics of activated carbon on adsorption of trimethoprim: Mechanisms study. RSC. Adv., 5: 85187-85195. 
Ncibi, M.C., R. Ranguin, M.J. Pintor, V. Jeanne-Rose and M. Sillanpaa et al., 2014. Preparation and characterization of chemically activated carbons derived from Mediterranean Posidonia oceanica (L.) fibres. J. Anal. Appl. Pyrolysis, 109: 205-214.

Nor, N.M., L.C. Lau, K.T. Lee and A.R. Mohamed, 2013. Synthesis of activated carbon from lignocellulosic biomass and its applications in air pollution control-A review. J. Environ. Chem. Eng., 1: 658-666.

Reffas, A., V. Bernardet, B. David, L. Reinert and M.B. Lehocine et al., 2010. Carbons prepared from coffee grounds by $\mathrm{H}^{3} \mathrm{PO}^{4}$ activation: Characterization and adsorption of methylene blue and Nylosan Red N-2RBL. J. Hazard. Mater., 175: 779-788.

Srenscek-Nazzal, J., W. Kaminska, B. Michalkiewicz and Z.C. Koren, 2013. Production, characterization and methane storage potential of $\mathrm{KOH}$-activated carbon from sugarcane molasses. Ind. Crops Prod., 47: 153-159.

Tran, V.T., D.T. Nguyen, V.T.T. Ho, P.Q.H. Hoang and P.Q. Bui et al., 2017. Efficient removal of $\mathrm{Ni}_{2}+$ ions from aqueous solution using activated carbons fabricated from rice straw and tea waste. J. Mater., 8: 426-437.
Uysal, T., G. Duman, Y. Onal, I. Yasa and J. Yanik, 2014. Production of activated carbon and fungicidal oil from peach stone by two-stage process. J. Anal. Appl. Pyrolysis, 108: 47-55.

Van Thuan, T., B.T.P. Quynh, T.D. Nguyen and L.G. Bach, 2017. Response surface methodology approach for optimization of $\mathrm{Cu}^{2}+, \mathrm{Ni}^{2}+$ and $\mathrm{Pb}^{2}+$ adsorption using $\mathrm{KOH}$-activated carbon from banana peel. Surf. Interfaces, 6: 209-217.

Van Tran, T., Q.T.P. Bui, T.D. Nguyen, V.T.T. Ho and L.G. Bach, 2017. Application of response surface methodology to optimize the fabrication of $\mathrm{ZnCl} 2$-activated carbon from sugarcane bagasse for the removal of $\mathrm{Cu}^{2}+$. Water Sci. Technol., 75: 2047-2055.

Wang, J. and S. Kaskel, 2012. $\mathrm{KOH}$ activation of carbon-based materials for energy storage. J. Mater. Chem., 22: $23710-23725$.

$\mathrm{Xu}$, J., L. Chen, H. Qu, Y. Jiao and J. Xie et al., 2014. Preparation and characterization of activated carbon from reedy grass leaves by chemical activation with H3PO4. Appl. Surf. Sci., 320: 674-680. 